\title{
METHODOLOGY FOR SENIOR-PROOF GUIDELINES: a practice example from the
}

\section{Netherlands}

Barbara C. van Munster, MD, PhD ${ }^{\mathrm{a}, \mathrm{b}}$

Johanna E.A. Portielje, MD, $\mathrm{PhD}^{\mathrm{C}}$

Andrea B. Maier, MD, $\mathrm{PhD}^{\mathrm{d}, \mathrm{e}}$

Arend J. Arends, $M D^{\mathrm{f}, \mathrm{g}}$

Johannes J.A. de Beer, MSc, PhD ${ }^{h}$

a University Groningen, University Medical Center Groningen, Department of Medicine, Groningen, The Netherlands,

${ }^{\mathrm{b}}$ Gelre Hospitals, Department of Geriatrics, Albert Schweitzerlaan 31, 7334 DZ Apeldoorn, The Netherlands

'Hagaziekenhuis, Department of internal medicine and oncology, Den Haag, The Netherlands, J.Portielje@hagaziekenhuis.nl

${ }^{\mathrm{d}}$ Department of Medicine and Aged Care, Royal Melbourne Hospital, University of Melbourne, Melbourne, Australia, Andrea.Maier@mh.org.au

${ }^{\mathrm{e}}$ Department of Human Movement Sciences, MOVE Research Institute Amsterdam, Vrije Universiteit Amsterdam, Amsterdam, The Netherlands.

fDutch Geriatrics Society (Dutch abbreviation: NVKG), Postbus 2704, 3500 GS Utrecht, The Netherlands, a.arends@havenziekenhuis.nl

${ }^{g}$ Havenziekenhuis, Department of Geriatrics, Haringvliet 2, Rotterdam, The Netherlands

hGuide2Guidance, jjadebeer@ziggo.nl

Corresponding Author: Barbara C. van Munster, MD, PhD, University Medical Center Groningen,

Department of Internal Medicine, Groningen, The Netherlands Tell: + 3155 5818395, e-mail:

b.van.munster@gelre.nl

This is the author manuscript accepted for publication and has undergone full peer review but has not been through the copyediting, typesetting, pagination and proofreading process, which may lead to differences between this version and the Version of Record. Please cite this article as doi: $10.1111 /$ jep.12738

This article is protected by copyright. All rights reserved. 


\section{Abstract}

Evidence-based-guidelines constitute a foundation for medical decision-making. It is often unclear whether recommendations in general guidelines also apply to older people. This study aimed to develop a methodology to increase the focus on older people in the development of guidelines. The methodology distinguishes four groups of older people: 1 . relatively healthy older people; 2 . older people with one additional specific (interfering) comorbid condition; 3 . older people with multimorbidity and 4 . vulnerable older people. The level of focus on older people required may be determined by the prevalence of the disease or condition, level of suffering, social relevance and the expectation that a guideline may improve the quality of care.

A specialist in geriatric medicine may be involved in the guideline process via participation, provision of feedback on drafts or involvement in the analysis of problem areas. With regard to the patient perspective, it is advised to involve organisations for older people or informal carers in the inventory of problem areas, and additionally to perform literature research of patient values on the subject. If the guideline focuses on older people, then the relative importance of the various outcome measures for this target group needs to be explicitly stated.

Search strategies for all the four groups are suggested. For clinical studies that focus on the treatment of diseases that frequently occur in older people, a check should be made regarding whether these studies produce the required evidence. This can be achieved by

This article is protected by copyright. All rights reserved. 
verifying if there is sufficient representation of older people in the studies and determining if there is a separate reporting of results applying to this age group.

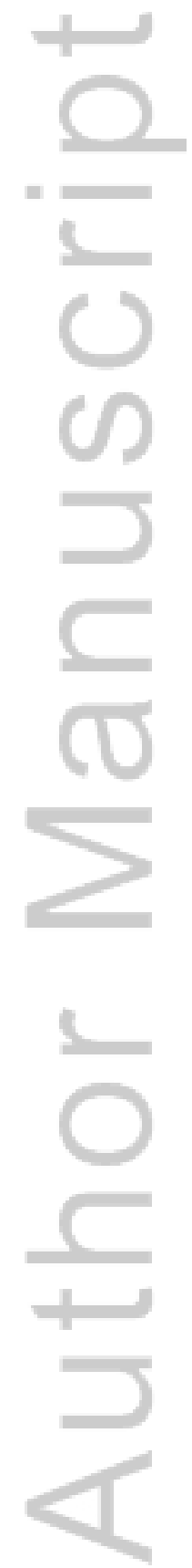

This article is protected by copyright. All rights reserved. 


\section{Introduction}

In current medical practice, evidence-based medicine featuring evidence-based guidelines constitutes an important foundation for medical decision-making. Evidence-based treatment of older people and their care is a constant challenge given that this category is significantly underrepresented in scientific research. A key cause of this underrepresentation is that both biomedical research and healthcare are largely organised around a single disease or disorder.(1) The older population - particularly frail older people - often suffer from multiorgan problems that require a more integrated approach.(2) One of the consequences of this underrepresentation of the older population in biomedical research, is that their frequently used medications have not been evaluated.(3) When older people do participate in trials, they are, for the most part, relatively healthy, have relatively little or no comorbidity and are often not frail.(4)

It has already become apparent in healthy older people that outcomes of treatment may differ from those of young adults with the same disease. It is to be expected for frail older people, or those with multimorbidity, that there will be further divergence. $(1,5)$ In addition, older people are often interested in other outcome measures, such as remaining independent, quality of life and the prevention of serious side effects. A shorter life expectancy also plays a role in the considerations, whilst shared decision-making on whether or not to treat can become complicated.(6) In short, the older population constitute a clinically heterogeneous group of individuals to whom the results of clinical-scientific research into young adults cannot automatically be applied. 
Currently, little attention has been paid to this (clinically heterogeneous) group of aged persons in guidelines and certainly not systematically i.e. in all stages of the development process of a guideline. One of the consequences is that it is often not clear whether the guideline recommendations do apply to older people. We aimed to develop a methodology to increase the focus on older people in the development of guidelines. This methodology is intended both for general guidelines and for guidelines that are specifically aimed at older people as a target group and it may be used by a guideline working group without specialists in aged care.

This article is protected by copyright. All rights reserved. 


\section{Methods}

A core group consisting of a specialist in internal medicine and geriatrics and two guideline methodologists wrote an initial draft text in 2014. This draft text was complementary to an existing Dutch baseline guideline methodology that already takes into account all basic steps for guideline development, including the finalization stage. The document was submitted to a working group of subject-matter specialists and a guideline methodologist for comments in several face to face meetings. In 2015 , the improved text was submitted to a sounding board group of subject-matter experts in the field of geriatric medicine, other diagnostic medical specialities or surgical specialities and/or experts in the field of guideline development. The suggestions and comments from the members of the sounding board group were processed by the core group, after which the revised version was submitted to the working group for final approval. Both core group, working group and sounding board group members were selected based on their personal interest and expertise and had no conflict of interest. Information about their background is supplied in the supplement as well as in the online version.(7) This version is commented and authorised by the Quality Council (Raad Kwaliteit) of de Dutch Medical Specialists, which sets quality standards for specialist care. The present version is the result of this.

Examples were searched for in literature. The framework for crafting clinical practice guidelines that are Relevant to the Care and Management of People with Multimorbidity of Uhlig was used as an useful example for the topics that had to be taken into account.(8) Two stages of guideline development were distinguished: the preparation stage and the

This article is protected by copyright. All rights reserved. 
development stage. The preparation stage starts from the moment the development of a guideline (de novo or an update) is considered. This includes the choice of a subject, establishing which organisations should be involved and lasts up to including the assembly of a working group. The development stage starts with a comprehensive analysis of problem areas, where a variety of stakeholders are heard. The development stage ends when the working group has a draft guideline ready.

\section{Results}

As treatment may differ dependent on the health state of the aged person, the methodology distinguishes four groups of older people, i.e. persons aged 65 and older. It is noted that category four partly overlaps with categories two and three:

1. Relatively healthy older people;

2. Older people with one additional specific (interfering) comorbid condition (disease, disorder). Interfering comorbidity refers to co-existing conditions that impact upon the disease or disorder which is the subject of the guideline, namely via 'drug-condition, drug-drug, and food-drug interactions'.(9) An example of interfering comorbidity is osteoporosis in older people with COPD.(10) Medication with corticosteroids in connection with COPD negatively impacts bone density and increases the risk of fractures.

3. Older people with multimorbidity (several co-existing chronic conditions), where it does not concern a single, specific comorbid condition;

This article is protected by copyright. All rights reserved. 
4. Frail older people. Vulnerability in older people is understood to mean 'the decrease of reserves and capacity through an accumulation of deficiencies in several domains'.(11) Frail older people have an increased risk of negative health outcomes, such as falls, delirium or functional limitations, non-specific symptoms such as extreme fatigue or unexplained weight loss, frequently occurring infections,(2) postoperative complications and mortality.(12)

\section{Preparation stage}

\section{Subject and objective}

The extent to which a specific focus on older people is required or desirable within a guideline may be determined by applying the criteria, as established by the Dutch Management Council for the Quality of Care for the choice of a subject, to the target group of older people.(13) These criteria are:

- the prevalence of the disease or condition;

- the level of suffering;

- $\quad$ the social relevance;

- the expectation that a guideline might improve the quality of care.

The decision to focus on a specific group of older people as defined above depends on whether or not prevalent interfering comorbidity or multimorbidity occurs in the target population of the guideline. For frail older people, what will mainly be important is whether 
prognosis, care organisation or outcome measures justify attention for this specific target group. The lack of scientific literature is, in itself, no reason not to pay attention to one of the groups of older people mentioned in the guideline.

In order to verify whether one of the groups of older people requires more or less focus than another, a 'quick search' of the literature may be performed where older-specific evidence in the form of systematic reviews of landmark studies may be examined. It is also possible to look at the availability of adjacent guidelines (that are currently being developed), or ask for the expertise of subject-matter specialists, in particular that of a specialist in geriatric medicine. It is recommended to state the decision to focus or not specifically on older people and its rationale, in the introduction to the guideline, where other considerations for the demarcation of the subject of the guideline are usually mentioned as well. Also, the target group it involves (older people, older people with one specific (interfering) comorbid condition, older people with multimorbidity or frail older people) and the starting questions that take this into account have to be made explicit.

Considerations for participation by a specialist in aged care and organisations for older people in guideline working groups

The composition of a working group for a guideline is initially determined by the subject. Based on the subject, the professional groups primarily involved are approached by the initiator. When the decision has been made to focus on older people, then this does not necessarily imply a specialist in geriatric medicine should participate in the working group. 
When most key questions on older pertain to relatively healthy older people or older people with an interfering comorbid condition that is (medically) treated, deployment may be limited to the provision of feedback within the framework of peer review. In case of an interfering comorbid condition it is also possible to consider a medical specialist in the field of this specific comorbid condition. When most key questions on older people pertain to those with multimorbidity, a choice between participation during the development stage and providing feedback during the development stage depends on the nature of the multimorbidity. When most key questions on older people pertain to frail older people, then participation or the provision of feedback during the development stage by a specialist in older medicine is an obvious choice.Development stage

\section{Inventory and analysis of problem areas}

The beliefs, values or preferences of older patients are of importance for the preparation of the appropriate recommendations, in particular during the weighing of the pros and cons of treatment options. Involvement of patient organisations for older people and organisations of informal carers within problem areas is therefore desirable. Additionally a literature research is recommended, preferably in MEDLINE and the Cochrane Library. 'Patient preferences', 'patient satisfaction', 'patient experiences', 'patient participation', 'physicianpatient relations' and 'shared decision-making' may be used as (controlled) keywords, in combination with the subject, and possibly limited to systematic reviews and/or older[tiab] or AGED[Mesh]. 


\section{Starting questions and outcome measures}

Next to outcome measures such as mortality and morbidity, it is desirable to consider outcome measures such as quality of life, hospitalisation, cognitive functioning, functional status or treatment burden in relation to older people. In addition, the required follow-up duration with regard to the outcome measures should be considered because this may be of importance in connection with the prognosis (think of the time-to-benefit). It is recommended to determine the relative importance of the outcome measures for this target group. The guideline development group should explicitly state which outcome measures are crucial and important.

Systematic search for evidence

For all the search strategies listed below, the search results may be narrowed down in a later stage to articles with a high average age, or studies in which meta-analyses (of individual patient data), subgroup analyses or results of meta-regression are reported in relation to treatment effect and interactions between treatment effect and comorbidity and/or age categories of older people.

For older people of category 1: as a general rule, the same search strategy will suffice as for younger adults.

This article is protected by copyright. All rights reserved. 
For older people of category 2: For this category of older people, keywords for the relevant comorbid condition need to be included in the search query.

For older people of category 3: For this category of older people, the following keywords are recommended (in PubMed)(14):

Chronic disease [MeSH Major Topic] OR Comorbidity [MeSH Major Topic] OR "Multiple chronic conditions" OR "Multiple chronic illnesses" OR "Multiple chronic diseases" OR "Multiple morbidity" OR "Multiple comorbidity" OR "Chronic condition" OR "Chronic illness" OR "Multiple conditions" OR "Multiple illnesses" OR "Multiple diseases" OR "Multimorbidity" OR "Multi morbidity" OR "Multi-morbidity" OR "Comorbid disease") AND Aged: $65+$ years

For older people of category 4: For this category of older people, the following keywords are recommended (in PubMed)(15):

"Frail Older"[Mesh] OR frail*[tiab] OR "short physical performance battery"[tiab] OR "Sarcopenia"[Mesh])

With respect to guidelines limited to the geriatric population, the search strategy of the geriatrics search filter is recommended.(16)

For studies on interventions, with a view to internal validity and the applicability of studies with regard to various categories of older people, combining well-performed (systematic reviews of) RCTs and observational studies, preferably prospective cohort research, may 
have added value. This depends on the importance of the key question as established by the working group in the preparation stage. For studies of diagnostic accuracy it is preferable to focus on systematic reviews on diagnostic test accuracy (assuming RCTs of diagnostic strategies are generally absent), or on studies with subgroup analyses and "age factors".

\section{Summarising study characteristics}

For clinical studies that focus on the treatment of diseases that frequently occur in older people, a check should be made regarding whether these studies produce the required evidence for elderly people by verifying:

- whether older people are well represented in the studies,

- whether it concerns a representative population of older people,

- whether the results (effectiveness and toxicity) of interventions in older people are specified separately.

Determining the quality of evidence for every outcome measure as well as the overall quality of evidence

The overall quality of evidence may vary for the different categories of older people because:

- various outcome measures may be used;

- the relative importance of an outcome measure may differ; and

This article is protected by copyright. All rights reserved. 
- the quality of evidence may differ for each outcome measure, among others, due to indirect evidence.

In the event of a lack of sub-group analyses or results of meta-regressions that give information on the effects of (diagnostic or therapeutic) interventions in older people, it may be checked whether effects for a specific outcome measure in studies that present overall results vary according to the average age of the study population or the percentage of patients with, for example, the relevant comorbidity in each study.

\section{Formulating and implementing recommendations}

When examining the balance of desired and undesired effects for (the various categories of) older people, consider:

- absolute benefits and absolute risks of interventions;

- $\quad$ medicine interactions;

- drug-disease interactions;

- treatment burden;

- $\quad$ physical, mental, and emotional capacity of a patient;

- prognosis (remaining life expectancy, functional status, years spent with limitations, quality of life) and

- the values and preferences of patients.

This article is protected by copyright. All rights reserved. 
When implementing recommendations for older people, consider what specific impeding factors (at the level of individual care providers, at the level of the organisation, and at the level of the system) exist for their application, and in particular how they may be addressed.

Although (national) approval and implementation is the most important but also hardest part, the finalization stage is not described in this methodology, because this stage is mostly determined by local organization of care. By including Dutch experts in the development of the methodology, we hope that we have created some support to facilitate the implementation. Before implementing this methodology in other countries it might be necessary to adjust the methods to the national process. In general, it is important to involve the geriatric or internal medicine society to review the guideline before finalization if they were not involved in the development. Creating public support by involving patient as well regulatory organizations as well as media might help in the final implementation of the recommendations for older people,

\section{Conclusion}

The epidemiologic approaches described above may help guideline developers as a type of checklist that should systematically be considered during guideline development. Although, ilmplementation of such a methodology is quite a challenge, we feel that given the risk of worse outcomes in a huge group of frail patients, researchers, guideline developers, and funding institutions should give first priority to the development of guidelines more appropriate for use in frail older persons with multimorbity.

This article is protected by copyright. All rights reserved. 


\section{Acknowledgements}

This methodology originated at the initiative of the Dutch Association of Internal Medicine

(Dutch abbreviation: NIV) and the Dutch Geriatrics Society (Dutch abbreviation: NVKG).

Special thanks to the working group: Ir. T.A. van Barneveld, G.S. Spronk, A.Y. Steutel.

This article is protected by copyright. All rights reserved. 


\section{References}

1. Townsley CA, Selby R, Siu LL. Systematic review of barriers to the recruitment of older patients with cancer onto clinical trials. J Clin Oncol. 2005;23(13):3112-24.

2. Clegg A, Young J, lliffe S, Rikkert MO, Rockwood K. Frailty in elderly people. Lancet. 2013;381(9868):752-62.

3. Watts G. Why the exclusion of older people from clinical research must stop. BMJ (Online). 2012;344(7858).

4. McMurdo MET, Roberts H, Parker S, Wyatt N, May H, Goodman C, et al. Improving recruitment of older people to research through good practice. Age and Ageing. 2011;40(6):659-65.

5. van de Glind EM, Rhodius-Meester HF, Reitsma JB, Hooft L, van Munster BC. Reviews of individual patient data (IPD) are useful for geriatrics: an overview of available IPD reviews. J Am Geriatr Soc. 2014;62(6):1133-8.

6. Scott IA, Guyatt GH. Cautionary tales in the interpretation of clinical studies involving older persons. Archives of Internal Medicine. 2010;170(7):587-95.

7.https://internisten.nl/sites/internisten.nl/files/Addendum\%20for\%20the\%20creation\%20of\%20sen ior-proof\%20guidelines.pdf [

8. Uhlig K, Leff B, Kent D, Dy S, Brunnhuber K, Burgers JS, et al. A framework for crafting clinical practice guidelines that are relevant to the care and management of people with multimorbidity. J Gen Intern Med. 2014;29(4):670-9.

9. Boyd $\mathrm{CM}$, Fortin $\mathrm{M}$. Future of multimorbidity research: How should understanding of multimorbidity inform health system design? Public Health Reviews. 2011;33(2):451-74.

10. Gibson PG, McDonald VM, Marks GB. Asthma in older adults. The Lancet. 2010;376(9743):803-13.

11. Lutomski JE, Baars MA, Boter $H$, Buurman BM, den Elzen WP, Jansen AP, et al. [Frailty, disability and multi-morbidity: the relationship with quality of life and healthcare costs in elderly people]. Nederlands tijdschrift voor geneeskunde. 2014;158:A7297.

12. Handforth C, Clegg A, Young C, Simpkins S, Seymour MT, Selby PJ, et al. The prevalence and outcomes of frailty in older cancer patients: A systematic review. Annals of Oncology. 2015;26(6):1091-101.

13. Care DMCftQo. Guideline for Guidelines 2012.

14. Guiding principles for the care of older adults with multimorbidity: an approach for c. Guiding principles for the care of older adults with multimorbidity: an approach for clinicians: American Geriatrics Society Expert Panel on the Care of Older Adults with Multimorbidity. J Am Geriatr Soc. 2012;60(10):E1-E25.

15. Bibas L, Levi $M$, Bendayan $M$, Mullie L, Forman DE, Afilalo J. Therapeutic interventions for frail elderly patients: Part I: Published randomized trials. Progress in Cardiovascular Diseases. 2014;57(2):134-43.

16. van de Glind EM, van Munster BC, Spijker R, Scholten RJ, Hooft L. Search filters to identify geriatric medicine in Medline. J Am Med Inform Assoc. 2012;19(3):468-72. 


\section{University Library}

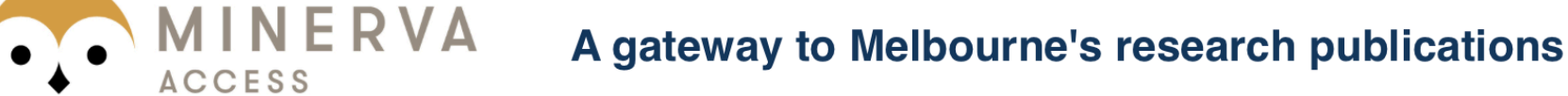

Minerva Access is the Institutional Repository of The University of Melbourne

\section{Author/s:}

van Munster, BC;Portielje, JEA;Maier, AB;Arends, AJ;de Beer, JJA

Title:

Methodology for senior-proof guidelines: A practice example from the Netherlands

\section{Date:}

2018-02-01

Citation:

van Munster, B. C., Portielje, J. E. A., Maier, A. B., Arends, A. J. \& de Beer, J. J. A. (2018).

Methodology for senior-proof guidelines: A practice example from the Netherlands.

JOURNAL OF EVALUATION IN CLINICAL PRACTICE, 24 (1), pp.254-257. https://

doi.org/10.1111/jep.12738.

Persistent Link:

http://hdl.handle.net/11343/292680 